\title{
ELECTRONIC AND STRUCTURAL PROPERTIES OF 5-HYDROXY-7-METOXYFLAVANONE: A THEORETICAL APPROACH
}

\author{
LUIS PADILLA-CAMPOS ${ }^{*}$ AND RAMÓN A. ZARATE ${ }^{2}$ \\ 'Departamento de Química, Facultad de Ciencias Básicas, Universidad de Antofagasta, \\ Casilla 170, Antofagasta, Chile \\ ${ }^{2}$ Departamento de Física, Facultad de Ciencias, Universidad Católica del Norte, \\ Casilla 1280, Antofagasta, Chile.
}

\begin{abstract}
Electronic and structural properties of two polymorphic modifications of 5-hydroxy-7-methoxyflavanone (pinostrobin) were theoretically investigated and compared with experimental crystallographic data. In the literature, four polymorphic modifications of pinostrobin had been reported. The present study has established that only two of them are relevant as they differ only in the position of the methoxy group whereas other structures are derived from the rotation of the phenyl group. Both structures differ in about $1.5 \mathrm{~kJ} / \mathrm{mol}$, but the activation energy of methoxy torsion was greater than $16 \mathrm{~kJ} / \mathrm{mol}$. In addition, both have similar electronic structures but it was established with slight differences in reactivity.
\end{abstract}

Keywords: pinostrobin, structural parameters, electronic structure, theoretical calculations.

\section{INTRODUCTION}

Flavonoids are polyphenolic compounds synthesized by plants, present in fruits, vegetables and herbs[1-6]. Flavonoids exhibit a several biological activities, as anti-bacterial, anti-inflamatory and anti-oxidant [7-10]. One of these flavonoids, pinostrobin (5-hydroxy-7-methoxyflavanone) had been identified and studied for about six decades for his potential therapeutic properties in various diseases such as cancer, considered as a good candidate for a leukemia chemopreventic agent or in the treatment of human mammary carcinoma [4, 11-14]. However, limitations in therapeutic applications in humans are due to low water solubility and in the present, investigations are being carried out to solve it [15]. In general, it has been proposed that these potential biological activities of natural flavonoids are due to its molecular structure identifying some characteristics that must be present to enhance their effect as a therapeutic agent with high activity are the location of the hydroxyl group in $\mathrm{A}, \mathrm{B}$ or $\mathrm{C}$-ring in the molecule and a double bond is required to be present in C2 and C3 position in C-ring [16-19]. Specifically in pinostrobin has been proposed that high anti-radical activity as the primary mechanism for inhibiting cancer cell activity is focused on a C-ring [20]. The latter is also valid for electrophilic attack, but not for a nucleophilic attack where would focus on a benzyl ring [20]. However, other study point that reactivity of different agents were focused only on A and C-ring (chromon ring) [21]. Thus, the reactivity towards various agents is unclear. From 1989 four structures of the pinostrobin had been reported, being each one is the polymorphic modification of pinostrobin and identified from two primary structures related to orientation of methoxy group with respect to the plane of chromon ring. The first structure was reported by Shoja [22] and the second also reported initially by Shoja [23]. However, the other two structures are derived from the second one and differing essentially by the orientation of the phenyl group with respect to the plane of chromon ring of the compound $[24,25]$. X-ray crystallographic data of three structures for second compound reported the torsion angles of phenyl group were $24.8^{\circ}, 38.5^{\circ}[23,24]$, and $85.6^{\circ}[25]$. For the first structure had been reported a torsion angle of phenyl group was $71.5^{\circ}$. A slight difference reported for all structure is that methoxy group is not coplanar with respect to the plane of chromon ring, and a reporting deviation is calculated between 2 and 6 degrees above or below of this plane. Thus, all structures have very similar structures and there are no studies reported if each of these structures has different reactivity or different conformations, in which the prevalence of one of the four structures can be favored by the conditions of synthesis of the compound.

Having into account the above considerations, the goal of the present work is to realize a theoretical study using quantum chemical calculations in order to determine the stability and molecular structure as well as the electronic properties of different conformations of pinostrobin and compare with experimental molecular structures and reactivity reported in the literature. This study will allow us first, elucidate if all reported structures can have an individual existence, and second, if all or some of these structures have different reactivity and compare with recent theoretical reports $[19,20]$.

\section{METHODOLOGY AND COMPUTATIONAL DETAILS}

Electronic and structural properties were performed at two levels of theoretical calculations: ab-initio post Hartree-Fock using second-order Møller-Plesset perturbation theory (MP2) [26-30] and density functional theory (DFT) using B3LYP functional [31-34]. For all atoms, 6-31G(d,p) basis set has been used $[35,36]$. Geometries of two major structures taken as a base which can generate all polymorphic modifications (structures I and II in Fig. 1) were fully optimized without symmetry restrictions using both levels of calculations. Other polymorphic structures can be generated by rotating the phenyl ring with respect to the plane of the chromon ring. The natural bond order (NBO) population analysis $[37,38]$ was used for the discussion of results. All the calculations have been done using the Gaussian 09 program [39].

To investigate the reactivity of both structures a Fukui analysis was made, calculating of atomic reactivity indexes using the proposed method by Contreras et al. [40] that allows to calculate atomic Fukui indexes $\left(\mathrm{f}^{(-)}, \mathrm{f}^{\left.\mathrm{f}^{+}\right)}\right.$, and $\mathrm{f}^{(\mathrm{O})}$ ) from only a single calculation of the electronic structure, without performing additional calculation involving ionic species of different spin multiplicity. $\mathrm{f}^{(-)}, \mathrm{f}^{(+)}$, and $\mathrm{f}^{(\mathrm{O})}$ are atomic Fukui functions for electrophilic, nucleophilic, and radical attacks, respectively.

\section{RESULTS AND DISCUSSION}

\section{GEOMETRIES AND ENERGETIC STABILITY}

In Table 1 the structural parameters, bond lengths, bond and selective torsion angles of two structures (I and II) of minimum energy determined at MP2 and B3LYP levels are displayed and they are compared with of two similar experimental structures $[22,24]$. Both theoretical structures are similar except in the orientation of methoxy group bonded to $\mathrm{C} 7$ of the chromon ring (see Fig. 1). From the point of view of the thermodynamic stability, the theoretical structure I is only $1.48 \mathrm{~kJ} / \mathrm{mol}$ at MP2 level (or $1.81 \mathrm{~kJ} / \mathrm{mol}$ at B3LYP level) and is more stable in comparison with structure II. In general MP2 and B3LYP calculations show that both theoretical structures are similar, in which structural parameters differ slightly from each other. When both structures are compared with experimental ones, bond lengths and bond angles have a good fit, within experimental error, where average differences are only 0.017 and 0.018 for structure I and II, respectively, at MP2 level of calculations. Similar behavior is found at B3LYP level (see Table 1). With respect to torsional angles, the greatest discrepancy in comparison to experimental data is found for the structure II with respect to $\mathrm{C} 2-\mathrm{C} 3-\mathrm{C} 4-\mathrm{C} 10$ and C11-O4-C7-C8, finding differences of $7.3^{\circ}$ (or $6.1^{\circ}$ ) and $4.1^{\circ}$ (or $5.1^{\circ}$ ) at MP2 level (or at B3LYP level), respectively. The second torsional angle corresponds to methoxy group and presents how it deviates (above or below) with respect to the molecular plane of chromon ring. Other difference found is the orientation of the phenyl group with respect to the molecular plane of chromon ring. From experimental data was found $71.5^{\circ}$ y $37.8^{\circ}$ for structures I and II, respectively $[22,24]$. In change, 
for theoretical structures was found a very similar orientation of the phenyl group, $66.2^{\circ}$ (or $62.7^{\circ}$ ) and $67.0^{\circ}$ (or $61.8^{\circ}$ ) for structures I and II at MP2 level (or at B3LYP level), respectively. Given these discrepancies, we decided to perform additional calculations with respect to the energy cost of conversion of the structure I in the II, involving the rotation of methoxy group and with respect to the orientation of the phenyl group with the plane of the chromon ring. The latter calculations were made with the fixed methoxy group, corresponding to structures I and II. The calculations were performed every $10^{\circ}$ of rotation for both, methoxy and the phenyl group, performing at each point of rotation a full optimization of the molecular structure. The results are displayed in Figures 2 and 3. From Fig. 2 we can see the methoxy group has an activation energy of $16.43 \mathrm{~kJ} / \mathrm{mol}$ predicted at MP2 level or $20.71 \mathrm{~kJ} / \mathrm{mol}$ predicted at B3LYP level. Despite the differences between the two levels of calculations, both show that at room temperature the conversion of a structure in other is little probable, predominating the structure (I or II), which is determined by experimental conditions of synthesis. Also, from Fig. 2 and considering that the energy of a $\mathrm{kT}$ at room temperature is about $1.5 \mathrm{~kJ} / \mathrm{mol}$, we concluded that methoxy group has a free rotation in about $20^{\circ}$ above and below with respect to the plane of chromon ring, which may explain the discrepancies between theoretical and experimental data. From Fig. 3 we can observe the phenyl group has activation energy at MP2 (B3LYP) level of $6.77(6.52) \mathrm{kJ} / \mathrm{mol}$ for structure I and 7.02 (6.41) kJ/mol for structure II (Fig. 3b). Furthermore, we can observe that both structures have a double peak in the activation energy at about $120^{\circ}$ and $180^{\circ}$ of rotation of the phenyl group. This latter result is explained by the maximum approach of the hydrogen atom bonded to the carbon C6' of the phenyl group with respect to the two hydrogen atoms bonded to carbon $\mathrm{C} 3$ of the chromon ring. The bond length is about $2.20 \AA$, producing an interatomic repulsion, which causes the two maxima in the activation energy in Fig. 3 for both structures and both levels of calculations. On the other hand, the phenyl group also has free rotation between $10^{\circ}$ and $95^{\circ}$ at room temperature, which may explain first, the discrepancy between experimental and theoretical structures and second, all polymorphic structures found for the structure II and informed in the literature [23-25].
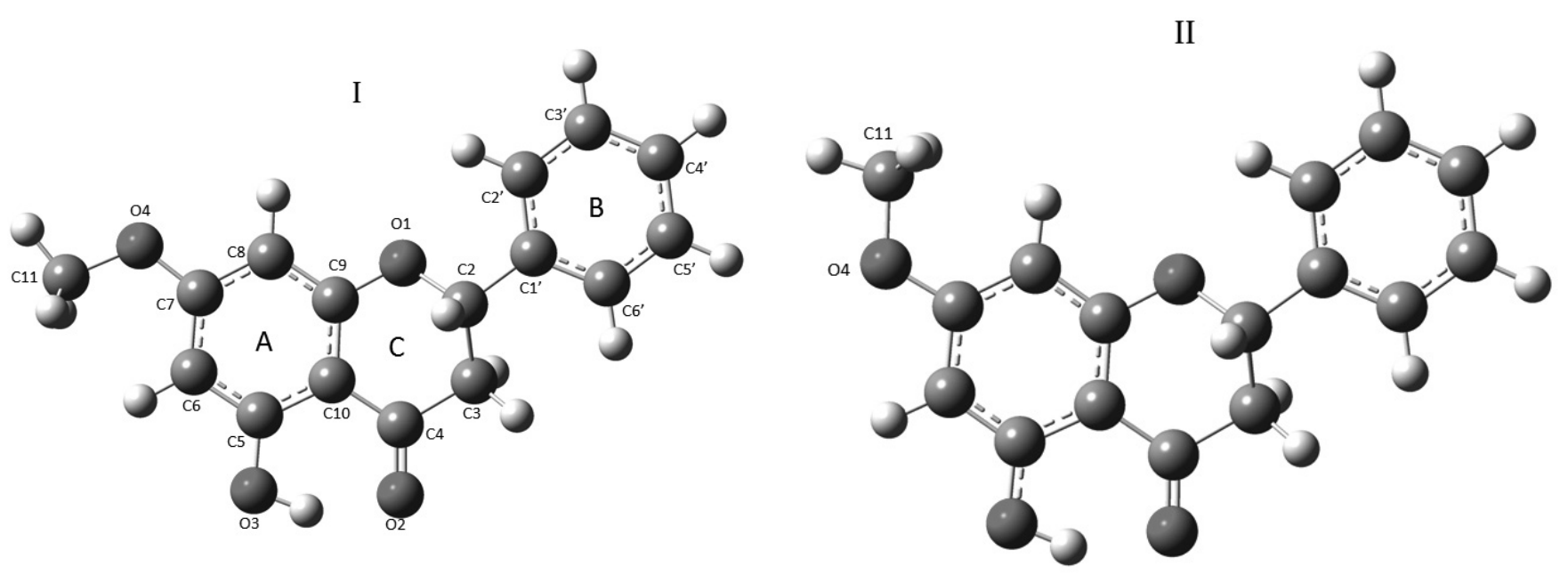

Figure 1. Molecular structure of two polymorphic modifications pinostrobin considered in the theoretical study.

Table 1. Selected experimental and optimized (MP2 and B3LYP in gas phase) with 6-31G(d,p) level geometric parameters for structures I and II. AD is the average difference between theoretical and experimental data in bond lengths and angles.

\begin{tabular}{|c|c|c|c|c|c|c|}
\hline Parameters & $\operatorname{EXP}(I)^{a}$ & MP2(I) & B3LYP(I) & $\operatorname{EXP}(I I)^{b}$ & MP2(II) & B3LYP(II) \\
\hline \multicolumn{7}{|c|}{ Bond lengths $(\AA)$} \\
\hline O1-C2 & $1.449(8)$ & 1.443 & 1.444 & $1.441(7)$ & 1.443 & 1.445 \\
\hline O1-C9 & $1.369(7)$ & 1.374 & 1.363 & $1.400(8)$ & 1.373 & 1.362 \\
\hline $\mathrm{O} 2-\mathrm{C} 4$ & $1.249(7)$ & 1.247 & 1.244 & $1.232(8)$ & 1.246 & 1.243 \\
\hline O3-C5 & $1.367(8)$ & 1.350 & 1.337 & $1.348(8)$ & 1.351 & 1.339 \\
\hline O4-C7 & $1.357(7)$ & 1.363 & 1.355 & $1.407(7)$ & 1.364 & 1.356 \\
\hline O4-C11 & $1.417(8)$ & 1.426 & 1.423 & $1.400(8)$ & 1.427 & 1.423 \\
\hline C1'-C2 & $1.536(9)$ & 1.501 & 1.512 & $1.51(1)$ & 1.500 & 1.512 \\
\hline $\mathrm{C} 1$ '-C2' & $1.360(10)$ & 1.400 & 1.400 & $1.353(9)$ & 1.400 & 1.400 \\
\hline $\mathrm{C} 1$ '-C6' & $1.390(10)$ & 1.398 & 1.400 & $1.406(9)$ & 1.398 & 1.399 \\
\hline $\mathrm{C2}-\mathrm{C} 3$ & $1.529(9)$ & 1.524 & 1.534 & $1.463(9)$ & 1.523 & 1.533 \\
\hline $\mathrm{C2}$ '-C3' & $1.390(10)$ & 1.394 & 1.395 & $1.40(1)$ & 1.394 & 1.395 \\
\hline $\mathrm{C} 3-\mathrm{C} 4$ & $1.496(9)$ & 1.510 & 1.517 & $1.53(1)$ & 1.510 & 1.518 \\
\hline C3'-C4' & $1.360(10)$ & 1.397 & 1.396 & $1.40(1)$ & 1.397 & 1.396 \\
\hline C4-C10 & $1.436(9)$ & 1.453 & 1.444 & $1.469(8)$ & 1.455 & 1.445 \\
\hline C4'-C5' & $1.330(15)$ & 1.396 & 1.395 & $1.34(1)$ & 1.396 & 1.395 \\
\hline C5-C6 & $1.378(9)$ & 1.396 & 1.398 & $1.405(9)$ & 1.388 & 1.390 \\
\hline C5-C10 & $1.411(8)$ & 1.415 & 1.424 & $1.433(9)$ & 1.421 & 1.430 \\
\hline
\end{tabular}




\begin{tabular}{|c|c|c|c|c|c|c|}
\hline \multicolumn{7}{|c|}{ Continuación tabla 1} \\
\hline C5'-C6' & $1.440(10)$ & 1.396 & 1.395 & $1.39(1)$ & 1.396 & 1.395 \\
\hline C6-C7 & $1.376(9)$ & 1.396 & 1.399 & $1.384(8)$ & 1.388 & 1.401 \\
\hline $\mathrm{C} 7-\mathrm{C} 8$ & $1.399(9)$ & 1.403 & 1.408 & $1.401(9)$ & 1.400 & 1.406 \\
\hline C8-C9 & $1.369(8)$ & 1.382 & 1.382 & $1.405(8)$ & 1.390 & 1.390 \\
\hline C9-C10 & $1.412(8)$ & 1.415 & 1.421 & $1.384(8)$ & 1.373 & 1.415 \\
\hline AD & & 0.017 & 0.018 & & 0.018 & 0.021 \\
\hline \multicolumn{7}{|l|}{ Bond angles $\left({ }^{\circ}\right)$} \\
\hline C2-01-C9 & $114.1(4)$ & 114.3 & 116.5 & $119.0(5)$ & 114.4 & 116.5 \\
\hline C7-O4-C11 & $118.9(5)$ & 117.0 & 118.8 & $116.4(5)$ & 117.1 & 119.0 \\
\hline $\mathrm{C} 2-\mathrm{C} 1 '-\mathrm{C} 2$ ' & $123.3(6)$ & 120.3 & 121.1 & $121.9(5)$ & 120.2 & 121.1 \\
\hline $\mathrm{C} 2-\mathrm{C} 1{ }^{\prime}-\mathrm{C} 6{ }^{\prime}$ & $114.6(7)$ & 119.9 & 119.7 & $116.5(6)$ & 120.0 & 119.7 \\
\hline $\mathrm{C} 2{ }^{\prime}-\mathrm{C} 1 '-\mathrm{C} 6{ }^{\prime}$ & $122.0(7)$ & 119.7 & 119.2 & $121.5(6)$ & 119.7 & 119.2 \\
\hline O1-C2-C1' & $106.2(5)$ & 107.6 & 108.2 & $112.2(5)$ & 107.6 & 108.2 \\
\hline $\mathrm{O} 1-\mathrm{C} 2-\mathrm{C} 3$ & $109.9(5)$ & 109.5 & 110.2 & $112.0(5)$ & 109.5 & 110.2 \\
\hline $\mathrm{C} 1 '-\mathrm{C} 2-\mathrm{C} 3$ & $108.8(6)$ & 112.5 & 112.9 & $114.6(6)$ & 112.7 & 113.0 \\
\hline C1'-C2'-C3' & $119.6(8)$ & 120.0 & 120.3 & $119.2(6)$ & 120.0 & 120.3 \\
\hline $\mathrm{C} 2-\mathrm{C} 3-\mathrm{C} 4$ & $110.5(5)$ & 110.1 & 111.0 & $113.2(6)$ & 110.1 & 111.0 \\
\hline C2'-C3'-C4' & $120.0(9)$ & 120.3 & 120.3 & $123.7(6)$ & 120.3 & 120.3 \\
\hline O2-C4-C3 & 121.1(5) & 121.4 & 121.0 & $121.0(6)$ & 121.3 & 120.9 \\
\hline $\mathrm{O} 2-\mathrm{C} 4-\mathrm{C} 10$ & $122.8(6)$ & 123.3 & 123.2 & $120.9(6)$ & 123.3 & 123.2 \\
\hline $\mathrm{C} 3-\mathrm{C} 4-\mathrm{C} 10$ & $116.2(5)$ & 115.3 & 115.8 & 118.1(5) & 115.4 & 115.8 \\
\hline C3'-C4'-C5' & $120.7(8)$ & 119.8 & 119.7 & 117.1(7) & 119.9 & 119.7 \\
\hline O3-C5-C6 & $118.8(5)$ & 117.7 & 118.8 & $116.1(6)$ & 118.5 & 119.3 \\
\hline O3-C5-C10 & $119.2(5)$ & 121.3 & 120.6 & $119.8(5)$ & 121.1 & 120.3 \\
\hline C6-C5-C10 & $122.0(6)$ & 121.0 & 120.7 & $124.0(6)$ & 120.4 & 120.4 \\
\hline C4'-C5'-C6' & $122.1(8)$ & 120.0 & 120.0 & $119.2(6)$ & 120.0 & 120.0 \\
\hline C1'-C6'-C5' & $115.4(8)$ & 120.2 & 120.5 & 124.1(6) & 120.2 & 120.5 \\
\hline $\mathrm{C} 5-\mathrm{C} 6-\mathrm{C} 7$ & $118.1(6)$ & 118.9 & 119.0 & $115.5(6)$ & 119.6 & 119.5 \\
\hline O4-C7-C6 & $123.3(6)$ & 123.9 & 123.7 & $111.2(5)$ & 114.8 & 115.1 \\
\hline O4-C7-C8 & $114.1(5)$ & 114.5 & 114.6 & $125.4(6)$ & 123.7 & 123.3 \\
\hline C6-C7-C8 & $122.6(6)$ & 121.5 & 121.7 & $123.3(5)$ & 121.5 & 121.7 \\
\hline C7-C8-C9 & $118.3(5)$ & 118.9 & 119.0 & 119.1(5) & 118.2 & 118.5 \\
\hline O1-C9-C8 & $116.7(5)$ & 117.0 & 117.4 & $117.6(5)$ & 116.1 & 116.7 \\
\hline O1-C9-C10 & $121.4(5)$ & 121.5 & 121.2 & $121.2(5)$ & 121.9 & 121.6 \\
\hline C8-C9-C10 & $121.8(5)$ & 121.5 & 121.3 & $121.2(6)$ & 122.0 & 121.7 \\
\hline C4-C10-C5 & $121.8(5)$ & 121.0 & 120.7 & $124.3(5)$ & 121.2 & 120.9 \\
\hline C4-C10-C9 & $120.8(5)$ & 120.4 & 120.8 & $118.7(6)$ & 120.2 & 120.7 \\
\hline C5-C10-C9 & $117.2(5)$ & 118.2 & 118.3 & $116.8(5)$ & 118.1 & 118.3 \\
\hline $\mathbf{A D}$ & & 1.3 & 1.3 & & 2.3 & 2.1 \\
\hline \multicolumn{7}{|l|}{ Torsion angles $\left({ }^{\circ}\right)$} \\
\hline O1-C9-C10-C4 & $-3.7^{c}$ & -6.1 & -4.2 & $-4.2^{\mathrm{d}}$ & -6.6 & -4.6 \\
\hline $\mathrm{C} 2-\mathrm{C} 3-\mathrm{C} 4-\mathrm{C} 10$ & $29.5^{\mathrm{c}}$ & 31.1 & 29.8 & $24.1^{\mathrm{d}}$ & 31.4 & 30.2 \\
\hline C2-O1-C9-C10 & $-25.2^{\mathrm{c}}$ & -23.4 & -22.8 & $-20.5^{\mathrm{d}}$ & -22.7 & -22.1 \\
\hline C3-C4-C10-C9 & $0.2^{\mathrm{c}}$ & 0.7 & 1.0 & $1.5^{\mathrm{d}}$ & 0.6 & 1.1 \\
\hline C11-O4-C7-C8 & $177.7^{\mathrm{c}}$ & 178.5 & 179.0 & $6.1^{\mathrm{d}}$ & 2.0 & 1.0 \\
\hline C11-O4-C7-C6 & $-2.6^{\mathrm{c}}$ & -0.5 & 0.4 & $176.9^{\mathrm{d}}$ & 180.0 & 179.7 \\
\hline
\end{tabular}

${ }^{a}$ From reference 22. ${ }^{b}$ From reference $24 .{ }^{c}$ Calculated from X-Ray diffraction data in ref. 22.

${ }^{\mathrm{d}}$ Calculated from X-Ray diffraction data in ref. 24. 


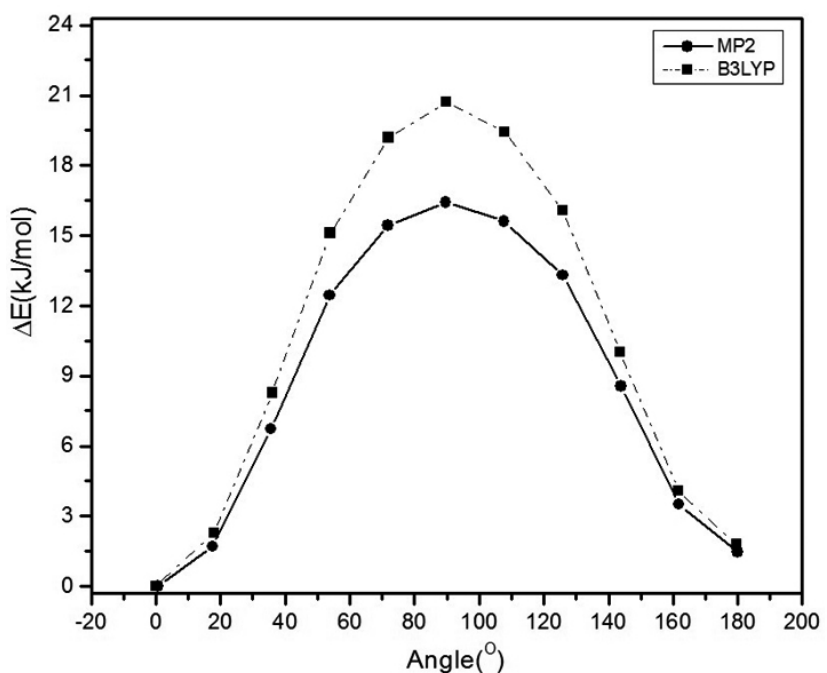

Figure 2. Relative rotational energy of the methoxy group.
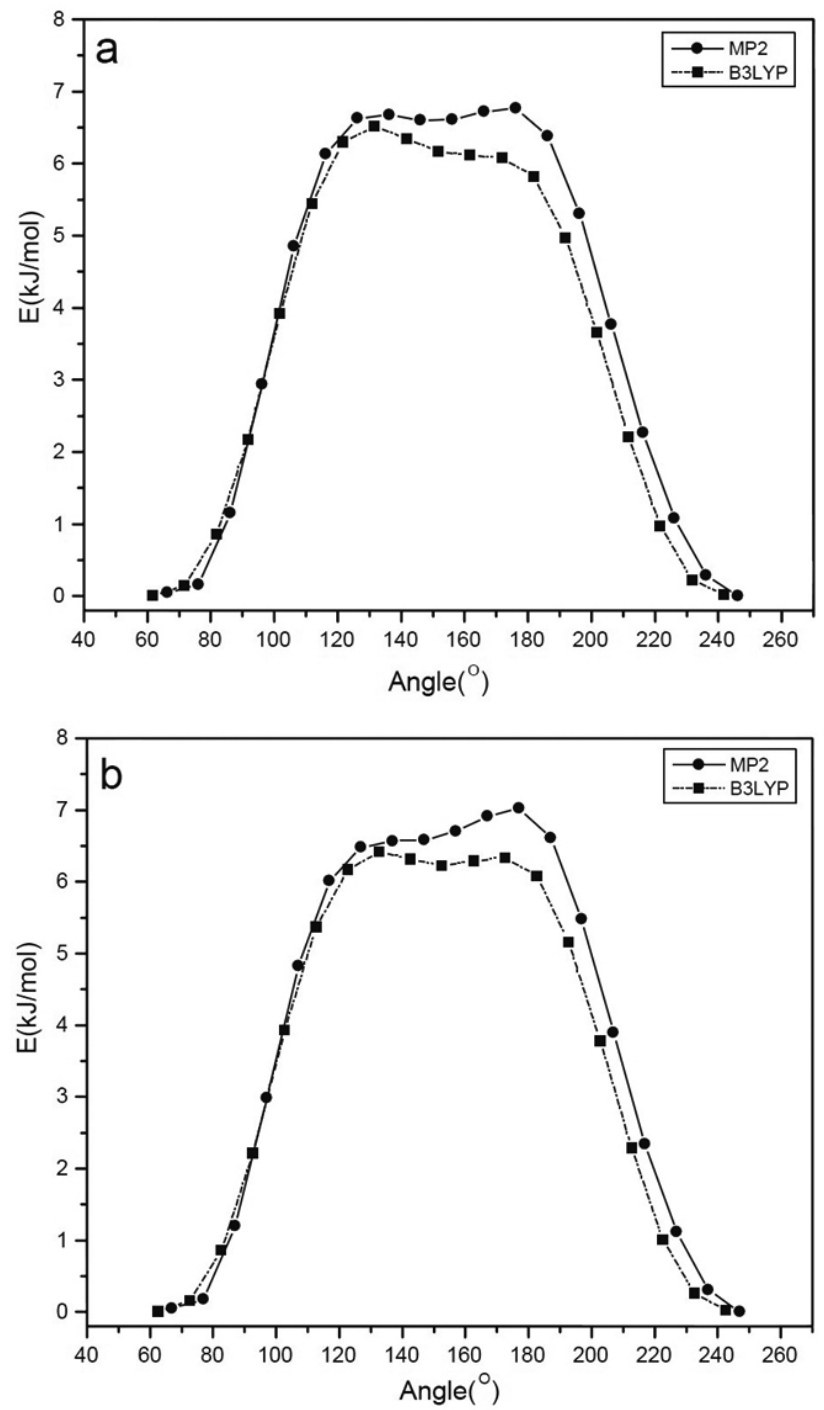

Figure 3. Relative rotational energy of the phenyl group for structures a) I and b) II.

\section{CHARGE DISTRIBUTION AND REACTIVITY}

Atomic net charges calculated using NBO procedure are displayed in Table 2 for both structures. MP2 and B3LYP calculations predict net charges in each atomic center for both structures are very similar with slight differences of only $0.01 \mathrm{e}$ to $0.14 \mathrm{e}$, centered mainly in the chromon ring. However, the analysis of both structures shows that C6 and C8 exhibit slight differences in the net charges, suggesting that might have different reactivity, modulated by the rotation of the methoxy group, transforming the structure I in the II. In addition, in pinostrobin the polarity of the structure is reduced as a result of intra-molecular hydrogen bonding between the carbonyl group at $\mathrm{C} 4$ with a hydroxy group at C5 [41], producing a low water solubility. Our calculations show that the dipole moment of the structure II (5.42 D at MP2 level) is greater than the structure I (2.37 D at MP2 level), indicating that the structure II would be slightly more soluble in water than I.

Table 2. Effective charges (Q) from Natural bond orbital (NBO) analysis for structure I and II. a) from MP2 and b) from B3LYP calculations. AD is the average difference between MP2 and B3LYP calculations.

\begin{tabular}{|c|c|c|c|c|}
\hline Atom & Q(e)-(I)(a) & $\mathbf{Q ( e ) - ( I ) ( b )}$ & $\mathbf{Q ( e ) - ( I I ) ( a )}$ & $\mathbf{Q ( e ) - ( I I ) ( b )}$ \\
\hline O1 & -0.615 & -0.529 & -0.617 & -0.530 \\
\hline O2 & -0.720 & -0.612 & -0.716 & -0.609 \\
\hline O3 & -0.773 & -0.687 & -0.771 & -0.687 \\
\hline O4 & -0.599 & -0.507 & -0.598 & -0.506 \\
\hline C2 & 0.142 & 0.088 & 0.142 & 0.088 \\
\hline C3 & -0.539 & -0.558 & -0.549 & -0.558 \\
\hline C4 & 0.701 & 0.556 & 0.700 & 0.556 \\
\hline C5 & 0.543 & 0.428 & 0.527 & 0.416 \\
\hline C6 & -0.469 & -0.410 & -0.425 & -0.368 \\
\hline C7 & 0.491 & 0.380 & 0.490 & 0.379 \\
\hline C8 & -0.419 & -0.362 & -0.464 & -0.405 \\
\hline C9 & 0.486 & 0.383 & 0.499 & 0.393 \\
\hline C10 & -0.420 & -0.324 & -0.416 & -0.322 \\
\hline C11 & -0.251 & -0.331 & -0.250 & -0.331 \\
\hline C1' & -0.071 & -0.064 & -0.072 & -0.064 \\
\hline C2' & -0.218 & -0.225 & -0.218 & -0.225 \\
\hline C3' & -0.221 & -0.229 & -0.222 & -0.229 \\
\hline C4' & -0.231 & -0.236 & -0.230 & -0.236 \\
\hline C5' & -0.223 & -0.230 & -0.222 & -0.230 \\
\hline C6' & -0.235 & -0.230 & -0.224 & -0.229 \\
\hline HO3 & 0.555 & 0.521 & 0.552 & 0.519 \\
\hline AD & 0.061 & & 0.060 & \\
\hline & & & & \\
\hline
\end{tabular}

It is known that the highest occupied molecular orbital (HOMO) and lowest unoccupied molecular orbital (LUMO) are the two main orbitals involving in reactivity chemistry. The HOMO energy presents the ability of molecular system to electron giving, LUMO presents the ability to electron accepting, and the gap HOMO-LUMO is associated to the molecular chemical stability. Thus, the plots for HOMO and LUMO orbitals at MP2 level for both structures are displayed in Fig. 4. HOMO and LUMO orbitals at B3LYP level present similar behavior and therefore they are not shown. We can see first, the electronic density is concentrated mainly on the chromon ring, second, LUMO exhibits the same behavior for both structures, suggesting the same ability to electron accepting and third, HOMO presents some differences for both structures, and the electronic density distribution suggests that these differences would be evident at the atomic or local level. The gap HOMOLUMO is $10.96 \mathrm{eV}$ for both structures showing the great structural stability of the compound. To investigate local reactivity, atomic Fukui indexes are shown in Fig. 5. We can see that for an electrophilic attack the O1, O3, C5, C6, C8, and $\mathrm{C} 9$ are the most relevant reactivity centers for structures I and II, showing C6 and C8 the higher reactivity, which are dependent of type of structure (see 
Fig. 5a). Thus, $\mathrm{C} 6$ and $\mathrm{C} 8$ have higher reactivity toward an electrophilic attack for structures I and II, respectively, showing the magnitude can be modulated by rotation of methoxy group. For a nucleophilic attack the $\mathrm{O} 2, \mathrm{C} 4, \mathrm{C} 7, \mathrm{C} 8$, and $\mathrm{C} 9$ present the higher reactivity, and they are similar for structures I and II, with $\mathrm{C} 4$ showing the higher reactivity of all atomic centers. The latter results are agreement with the results found from the LUMO analysis. For a radical attach $\mathrm{O} 1, \mathrm{C} 4$ to $\mathrm{C} 9$ of the chromon ring, and also $\mathrm{O} 2$ and $\mathrm{O} 3$ present the higher reactivity, with $\mathrm{C} 6$ and $\mathrm{C} 8$ having the higher reactivity for structures I and II, respectively, whose behavior for these last two centers is similar to that found for the electrophilic attack. The latter results are similar with theoretical results recently reported by R. D. Vargas-Sánchez et al. [20]. They concluded using similar parameters (Fukui indexes) from DFT calculations that reactivity towards electrophilic and radical attack were focused on the chromon ring, but the preferential position of higher reactivity is different from our results (O1 and $\mathrm{H} 3$ versus $\mathrm{C} 6$ ( or $\mathrm{C} 8$ ) in our case). However, the biggest difference is in the nucleophilic attack, where they predicted that the higher reactivity was on the benzyl ring, preferentially on the position H4' in comparison with our results that is focused on the chromon ring, preferentially on the position $\mathrm{C} 4$.

Structure I

Structure II
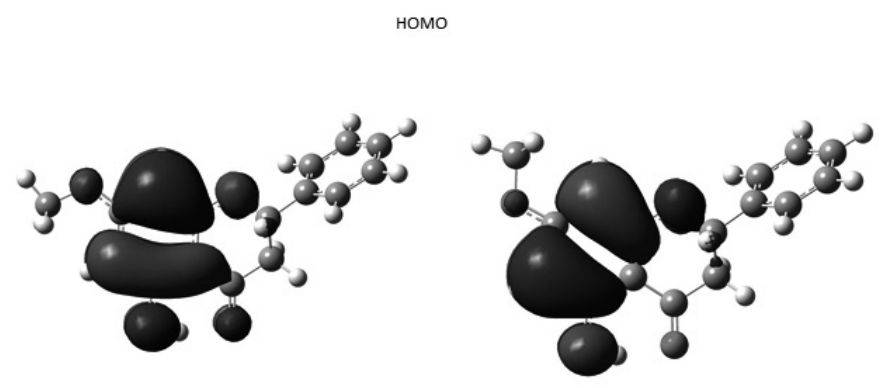

LUMO
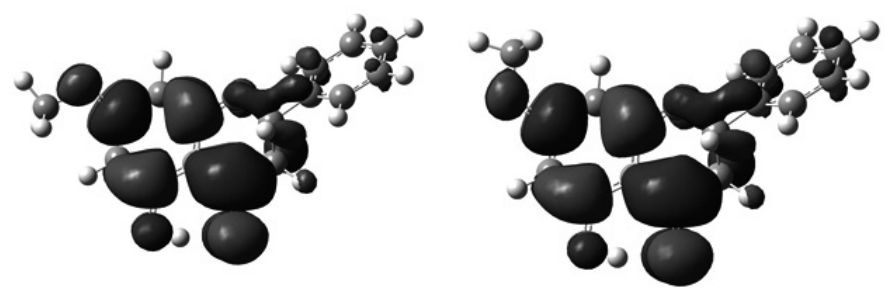

Figure 4. Plots of the electronic density of HOMO and LUMO orbitals for structures I and II at MP2 level.

\section{CONCLUSIONS}

Electronic and structural properties of two polymorphic modifications of 5-hydroxyflavanone (pinostrobin) were theoretically investigated at MP2 and B3LYP levels of calculations and compared with experimental crystallographic data and theoretical calculations of reactivity. The calculations predict that both structures differ in about $1.50 \mathrm{~kJ} / \mathrm{mol}$, but the activation energy with respect to methoxy torsion that involved the conversion of the structure I in the II was greater than $16 \mathrm{~kJ} / \mathrm{mol}$. The latter result showed the great stability of structures I and II. Futhermore, it was found activation energy for the rotation of phenyl group is greater than $6 \mathrm{~kJ} / \mathrm{mol}$, but the phenyl group can have a free rotation between $10^{\circ}$ and $95^{\circ}$ at room temperature. The latter results and the good fit found between theoretical and experimental structural parameters, can explain all polymorphic structures found experimentally, which may be derived from structures I and II. Finally, although both structures have similar electronic charge distribution, however, they presented slight differences in reactivity, focused mainly in the chromon ring. The latter differ slightly from the recently reported theoretical results [20] but are in agreement with the experimental evidence [21].
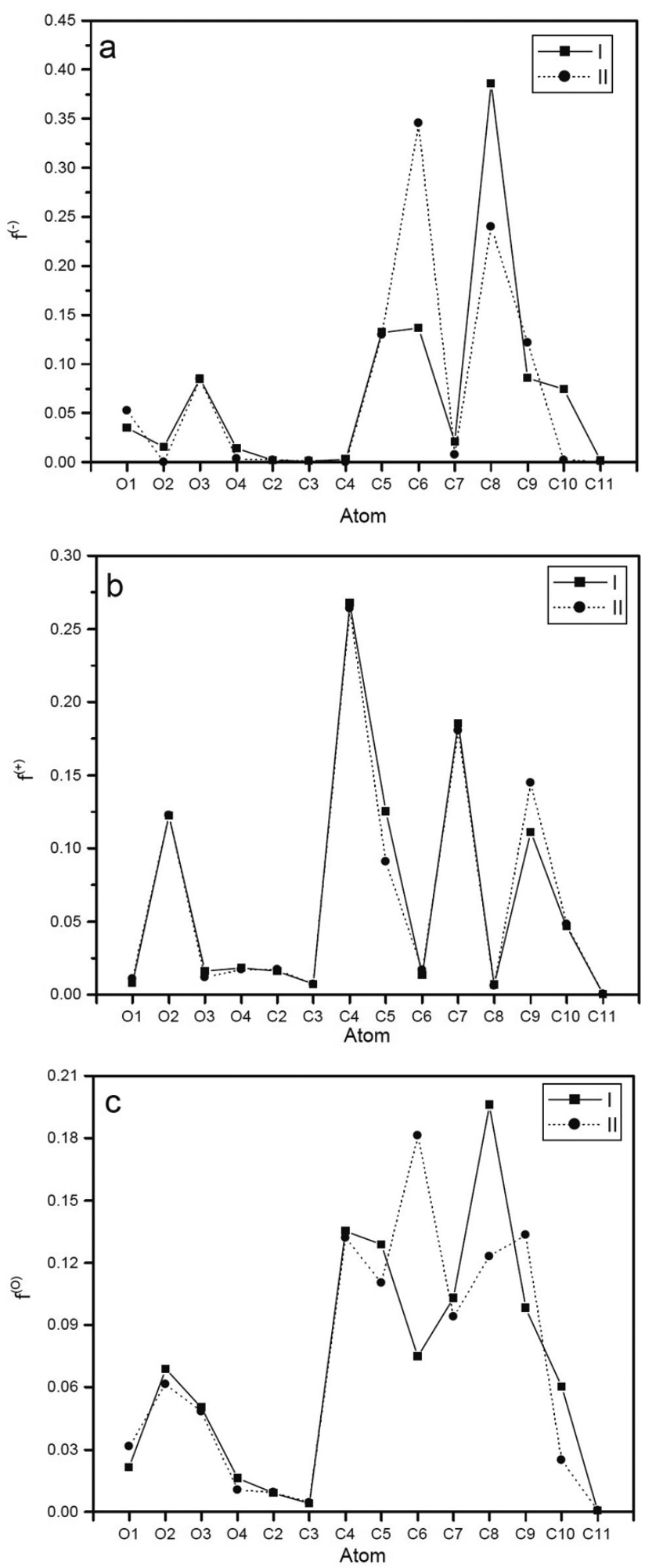

Figure 5. Atomic Fukui indexes of reactivity: a) $\left.\mathrm{f}^{(-)}, \mathrm{b}\right) \mathrm{f}^{(+)}$, and c) $\mathrm{f}^{(\mathrm{O})}$ Continue line for structure I and dashed line for structure II at MP2 level.

\section{AKCNOWLEDGEMENTS} 204.

This work was supported by FONDECYT Anillo project, Grant ACT- 


\section{REFERENCES}

1.- G.R Beecher, J. Nutr. 10, 3248S, (2003)

2.- J.V. Formica, W. Regelson, J. Food Chem.Toxicol. 3, 1061, (1995)

3.- S.N. López, M.G. Sierra, S.J. Gattuso, R.L. Furlán, S.A. Zacchino, Phytochemistry. 67, 2152, (2006)

4.- H.D Smolarz, E. Mendyk, A. Bogucka-Kocka, J. Kocki, Z Naturforsch C. 61, 64, (2006)

5.- W. Wangkangwan, S. Boonkerd, W. Chavasiri, K. Sukapirom, K. Pattanapanyasat, N. Kongkathip, T. Miyakawa, C. Yompakdee, Biosci. Biotechnol.Biochem. 73, 1679, (2009)

6.- A. Nix, C.A. Paull, M. Colgrave, SpringerPlus. 4, 1, (2015)

7.- J.W. Fahey, K.K. Stepheson, J.Agric.Food Chem. 50, 7472, (2002)

8.- N.A. Yusuf, M. Suffian, M. Annuar, N. Khalid, AJCS. 7, 730, (2013)

9.- T. Sudai, S. Prabpai, P. Kongsaeree, C. Wattapiromsakul, S. Tewtrakul, J. Ethnopaharm. 154, 453, (2014)

10.- N.K. Patel, K.K. Bhutani, Phytomedicine. 21, 946, (2014)

11.- G. Smistad G., J. Jacobsen, S.A. Sande, Int.J.Pharmac. 330, 14, (2007)

12.- J.S. Ashidi, P.J. Houghton, P.J. Hylands, S. Sieber, T. Efferth, Planta Medica. 73, 855, (2007)

13.- J.C. Le Bail, L. Aubourg, G. Habrioux, Cancer Letter. 156, 37, (2000)

14.- N.K. Patel, G. Jaiswal, K.K. Bhutani, Nat.Prod. Res. 30, 2017 (2016)

15.- A.E. Radi. S. Eissa, J. Open Chem.Biomed.Meth. 3, 74, (2010)

16.- K.L. Wolfe, R.H. Liu, J. Agric. Food Chem. 56, 8404, (2008)

17.- H. Jiye, W. Yoonkyung, H. Do-seok, J. Geunhyeong, E. Sunglock, L. Younggiu, C.P. Jun, L. Yoongho, Bioorg. Med.Chem.Lett. 20, 5510, (2010)

18.- C. Yaung-Hung, Y. Zhi-Shiang, W. Chi-Chung, C. Yeong-Sheng, W. BoCheng, H. Chih-Ang, S. Tzenge-Lien, Food Chem. 134, 717, (2012)

19.- K. Hassanzadeh, K. Akhtari, H. Hassanzadeh, S. Amir-Zarei, N. Fakhraei, K.Hassanzadeh, Food Chem. 164, 251 (2014)

20.- R.D. Vargas-Sánchez, A.M. Mendoza-Wilson, G.R. Torrescano-Urrutia, A. Sánchez-Escalante, Comp.Theo.Chem. 1066, 7, (2015)

21.- E.A. Plazas, L.E. Cuca, W.A. Delgado, Rev.Colomb.Quím, 37, 135, (2008)

22.- M.Shoja, Z.Kristallographie. 189, 89, (1989)

23.- M. Shoja, Acta Cryst. C45, 828, (1989)

24.- V.I. Yamovoi, E.A. Kul'magambetova, A.T. Kulyyasov, K.M. Turdybekov, S.M. Adekenov, Chem.Nat.Comp. 37, 424, (2001)

25.- I. Brito, M.J. Simirgiotis, A. Brito, M. Rodriguez Werner, J. Borquez, P. Wintherhalter, A. Cardenas, J.Chi.Chem.Soc. 60, 2864, (2015)

26.- M. Head-Gordon, J.A. Pople, M.J. Frisch, Chem.Phys.Lett. 153, 503, (1988)

27.- S. Saebo, J. Almlöf, Chem.Phys.Lett. 154, 83, (1989)

28.- M.J. Frisch, M. Head-Gordon, J.A. Pople, Chem.Phys.Lett. 166, 275, (1990)

29.- M.J. Frisch, M. Head-Gordon, J.A. Pople, Chem.Phys.Lett. 166, 281, (1990)

30.- M. Head Gordon, T. Head-Gordon, Chem.Phys.Lett. 220, 122, (1994)

31.- A.D. Becke, J.Chem.Phys. 98, 5648, (1993)

32.- A.D. Becke, Phys.Rev.A. 38, 3098, (1988)

33.- B. Miehlich, A. Savin, H. Stoll, H. Preuss, Chem.Phys.Lett. 157, 200, (1989)

34.- C. Lee, W. Yang, R.G. Parr, Phys.Rev.B. 37,785, (1988)

35.- G.A. Petersson, A. Bennett, T.G. Tensfeldt, M.A. Al-Laham, W.A. Shirley and J. Mantzaris, J.Chem.Phys. 89, 2193, (1988)

36.- G.A. Petersson, M.A. Al-Lahman, J.Chem.Phys. 94, 6081, (1991)

37.- J. E. Carpenter, F. Weinhold, J.Mol.Struct.(Theochem). 46, 41, (1988)

38.- F. Weinhold, J.E. Carpenter, The Structure of Small Molecules and Ions, Plenum, New Yok, 1988

39.- M. J. Frisch, G. W. Trucks, H. B. Schlegel, G. E. Scuseria, M. A. Robb, J. R. Cheeseman, G. Scalmani, V. Barone, B. Mennucci, G. A. Petersson, H. Nakatsuji, M. Caricato, X. Li, H. P. Hratchian, A. F. Izmaylov, J. Bloino, G. Zheng, J. L. Sonnenberg, M. Hada, M. Ehara, K. Toyota, R. Fukuda, J. Hasegawa, M. Ishida, T. Nakajima, Y. Honda, O. Kitao, H. Nakai, T. Vreven, J. A. Montgomery, Jr., J. E. Peralta, F. Ogliaro, M. Bearpark, J. J. Heyd, E. Brothers, K. N. Kudin, V. N. Staroverov, T. Keith, R. Kobayashi, J. Normand, K. Raghavachari, A. Rendell, J. C. Burant, S. S. Iyengar, J. Tomasi, M. Cossi, N. Rega, J. M. Millam, M. Klene, J. E. Knox, J. B. Cross, V. Bakken, C. Adamo, J. Jaramillo, R. Gomperts, R. E. Stratmann, O. Yazyev, A. J. Austin, R. Cammi, C. Pomelli, J. W. Ochterski, R. L. Martin, K. Morokuma, V. G. Zakrzewski, G. A. Voth, P. Salvador, J. J. Dannenberg, S. Dapprich, A. D. Daniels, O. Farkas, J. B. Foresman, J. V.
Ortiz, J. Cioslowski, and D. J. Fox, Gaussian 09, Revision B.01, Gaussian, Inc., Wallingford CT, 2010.

40.- R.R. Contreras, P. Fuentealba, M. Garván, P. Pérez, Chem.Phys.Lett. 304, 405, (1999)

41.- A. Parwata, Y. Sukardiman, H.S. Mulja, A. Widhiartini, A. Gunawan, Pure Appl.Chem.Sci., 3, 19, (2015) 